Gefässchirurgie 2019 $24: 220-227$ https://doi.org/10.1007/s00772-019-0524-y Published online: 24 April 2019

(C) The Author(s) 2019
M. Trenner · H.-H. Eckstein · M. A. Kallmayer · B. Reutersberg · A. Kühnl

Klinik und Poliklinik für Vaskuläre und Endovaskuläre Chirurgie, Klinikum rechts der Isar, Technische Universität München, Fakultät für Medizin, Munich, Germany

\title{
Secondary analysis of statutorily collected routine data
}

\section{Strengths, limitations and examples of use}

\section{Background}

Randomized controlled trials (RCT) are the gold standard for the assessment of medical treatment and when implementing new treatment strategies RCTs are indispensable; however, the population and treatment settings of RCTs often do not reflect the real-world setting. Registries try to capture real-world data but these are often voluntarily collected and data validity is often considered questionable due to certain risks of bias (e.g. selection bias and information bias), especially in the absence of independent external data validation [35]. Numerous healthcare data are statutorily collected for other purposes (e.g. quality assurance in carotid artery interventions, hospital remuneration). This article focuses mainly on the strengths and limitations of the analysis of these data sources and gives an overview of typical applications and the current literature.

\section{Definition}

In contrast to primary data analysis that uses data collected for a prespecified purpose (e.g. RCTs), secondary data analysis uses data that were originally collected for a different purpose or expands the originally intended purpose of primary data collections, e.g. diagnosis-related groups (DRG) data and external quality assurance [29].

\section{Legal background}

This article focuses on secondary data analysis of statutorily collected routine data. The main databases used for these analyses in vascular surgery in Germany are DRG data collected by the German Federal Statistical Office (Deutsches Statistisches Bundesamt, DeStatis) and quality assurance data for carotid artery procedures, collected by the Institute for Quality Assurance and Transparency in the Healthcare System (Institut für Qualitätssicherung und Transparenz im Gesundheitswesen, IQTIG) pursuant to $\$ 137$ a of the German Social Security Code Book V (Sozialgesetzbuch, SGB V).

\section{DRG data collected by DeStatis}

Based on $\$ 21$ of the Hospital Reimbursement Act (Krankenhausentgeldgesetz, KHEntG) DRG data of all inpatients treated in German hospitals (apart from military hospitals and psychiatric institutions) are annually transmitted to the Institute for the Hospital Remuneration System (Institut für das Entgeldsystem im Krankenhaus, InEK). Primary use of this data collection is improvement of the DRG remuneration system. These data are forwarded to DeStatis for the purpose of official hospital statistics (Amtliche Krankenhausstatistik). According to $\$ \$ 3 \mathrm{a}$ and 16 of the Federal Statistics Act (Bundesstatistikgesetz) these microdata can be used for scientific purposes $[27,29,31]$. To facilitate this process, DeStatis implemented research data centers (Forschungsdatenzentren, FDZ).

\section{Quality assurance data collected by the Institute pursuant to $\S 137 a$ SGB V (eQS data)}

Pursuant to $\$ 137$ a of the SGB V, the German Federal Joint Committee (Gemein- samer Bundesausschuss, G-BA) commissioned the Institute for Applied Quality Improvement and Research in Health Care (aQua Institute) in 2009 to develop and implement external quality assurance in the German healthcare system. Among other procedures, all inpatient procedures performed to treat a narrowed extracranial internal carotid artery have to be reported for external quality assurance. This applies for all German Hospitals registered under $₫ 108$ SGB V [16]. In 2015 the aQua Institute was followed by the IQTIG on the same legal basis.

\section{Methods and data sources of secondary data analysis}

For DRG microdata, access has to be granted by DeStatis after an official application has been handed in by researchers. Data processing can then be conducted through controlled remote data processing (Kontrollierte Datenfernverarbeitung), as a guest researcher in a FDZ or receiving a scientific use file (SUF). When using remote data processing, the researcher receives a sample data set that contains the same characteristics as the original data set but with randomly inserted values. Using this sample data set, an analysis script is used for remote data access. After sending this script to DeStatis it will be applied on the original data set and the researcher will receive only the results. A guest researcher in an FDZ is granted access to an anonymized data collection using a computer working place within the FDZ. Data collections can be processed but are not allowed 
Hier steht eine Anzeige.

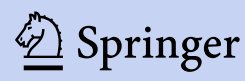




\begin{tabular}{|c|c|c|c|c|}
\hline & DeStatis DRG microdata & Statutory quality assurance ${ }^{a}$ & $\begin{array}{l}\text { Health insurance claims } \\
\text { data }\end{array}$ & Voluntary registries \\
\hline Legal background & Statutory data collection & Statutory data collection & Statutory data collection & Voluntary participation \\
\hline Coverage & $\begin{array}{l}\text { All in-hospital cases except } \\
\text { military and psychiatric } \\
\text { hospital }\end{array}$ & $\begin{array}{l}99.1 \% \text { of carotid artery procedures } \\
\text { [16] }\end{array}$ & $\begin{array}{l}\text { Patient data on insurees of } \\
\text { the respective insurance } \\
\text { company }\end{array}$ & $\begin{array}{l}\text { Depending on participa- } \\
\text { tion, mostly small samples }\end{array}$ \\
\hline $\begin{array}{l}\text { Original purpose of } \\
\text { data collection }\end{array}$ & Hospital remuneration & External quality assurance & $\begin{array}{l}\text { Administration and remu- } \\
\text { neration }\end{array}$ & $\begin{array}{l}\text { Depending on registry, } \\
\text { mostly quality assurance } \\
\text { and research }\end{array}$ \\
\hline Collected data & $\begin{array}{l}\text { Standard demographic } \\
\text { data, length of stay, ICD } \\
\text { code for main and sec- } \\
\text { ondary diagnoses, OPS } \\
\text { codes for procedures in } \\
\text { this admission, reason for } \\
\text { discharge, others }\end{array}$ & $\begin{array}{l}\text { Standard demographic data, length } \\
\text { of stay, clinical details (e. g. degree } \\
\text { of carotid stenosis), performed } \\
\text { procedures, procedural details, } \\
\text { clinical complications and others }\end{array}$ & $\begin{array}{l}\text { Standard demographic } \\
\text { data, length of stay, ICD } \\
\text { codes for hospital stays } \\
\text { and ambulatory treatment, } \\
\text { drug and cure prescrip- } \\
\text { tions, OPS/EBM codes } \\
\text { for procedures, disability } \\
\text { periods, others }\end{array}$ & $\begin{array}{l}\text { Depending on registry and } \\
\text { purpose }\end{array}$ \\
\hline Follow-up period & $\begin{array}{l}\text { In-hospital stay (case per- } \\
\text { spective) }\end{array}$ & In-hospital stay (case perspective) & $\begin{array}{l}\text { Longitudinal follow-up } \\
\text { possible (patient perspec- } \\
\text { tive) }\end{array}$ & $\begin{array}{l}\text { Longitudinal follow-up } \\
\text { possible (patient perspec- } \\
\text { tive) }\end{array}$ \\
\hline \multicolumn{5}{|l|}{ Risk of ... } \\
\hline Selection bias & $\begin{array}{l}\text { Low for inpatients } \\
\text { (outpatients not included) }\end{array}$ & $\begin{array}{l}\text { Low for treated patients } \\
\text { (non-treated or miscoded patients } \\
\text { not included) }\end{array}$ & $\begin{array}{l}\text { Intermediate } \\
\text { (only patients of selected } \\
\text { insurance companies } \\
\text { included) }\end{array}$ & $\begin{array}{l}\text { Intermediate to high, de- } \\
\text { pending on participating } \\
\text { centers and policy for in- } \\
\text { clusion }\end{array}$ \\
\hline Information bias & $\begin{array}{l}\text { Low regarding "hard" out- } \\
\text { comes such as in-hospital } \\
\text { mortality, intermediate for } \\
\text { other outcomes depend- } \\
\text { ing on data validation by } \\
\text { the MDK }\end{array}$ & $\begin{array}{l}\text { Intermediate, depending on internal } \\
\text { and external data validation }\end{array}$ & $\begin{array}{l}\text { Low regarding "hard" out- } \\
\text { comes, intermediate for } \\
\text { other outcomes depend- } \\
\text { ing on data validation by } \\
\text { the MDK }\end{array}$ & $\begin{array}{l}\text { Low to high, depending on } \\
\text { data validation policies of } \\
\text { the register }\end{array}$ \\
\hline \multicolumn{5}{|c|}{$\begin{array}{l}\text { DRG diagnosis-related groups, aQua Institute for Applied Quality Improvement and Health Care, ICD International Code of Diseases, OPS Operation and } \\
\text { Procedure Code, MDK Health Insurance Medical Service (Medizinischer Dienst der Krankenversicherungen), EBM Uniform Rating Scale (Einheitlicher } \\
\text { Bewertungsmaßstab) } \\
\text { a Carotid artery revascularization as example, among other entities }\end{array}$} \\
\hline
\end{tabular}

to leave the facilities of DeStatis. An SUF is supplied by DeStatis and contains highly anonymized data sets on CDs or DVDs. The high degree of anonymization is associated with a certain degree of information loss, which makes SUF inapplicable for many scientific issues, such as volume-outcome analysis or indepth analysis of risk factors for procedures [27]. Controlled remote data processing may also be used to work with eQS data. It is important to mention that DRG and eQS data are based on hospitalization times of cases. So far, it is not possible to longitudinally follow a patient for a longer period of time or e.g. identify redo operations once a patient has left the hospital.

Reporting of secondary data analysis of German routine data should follow the standardized reporting rou- tine for secondary analyses (STandardisierte BerichtsROutine für Sekundärdaten Analysen, STROSA 2) guidelines [28]. The STROSA 2 is a modification of the internationally established RECORD guidelines that address specific characteristics of the German healthcare system.

\section{Strengths and limitations}

The main strengths and limitations of statutorily collected data compared to health insurance claims data and voluntary registries are summarized in

\section{- Table 1.}

The main strength of statutorily collected data is the coverage, which reduces the risk of a selection bias. DeStatis DRG microdata are collected for all inpatients, except patients in military hos- pitals and psychiatric institutions. Consequently DRG microdata can give a full nationwide survey on hospital incidences of a disease and the in-hospital treatment. With $99.1 \%$ of all cases of carotid artery revascularizations performed in Germany, the statutory quality assurance registry (eQS) is very close to a complete survey. Most of the missing $0.9 \%$ of patients were treated at the end of the year of interest but discharged after the deadline in the following year (15 February). This means selection bias regarding performed procedures may be considered low in these databases [16]. Health insurance data are limited to the patients of the selected insurance company and registries are highly dependent on participation of centers and their policy for inclusion, which leads to a selection of cases 
(insuree or patients who were treated in a participating center).

The risk of information bias of a database is driven by the original purpose as well as the extent and validity of the collected data. Looking at DeStatis DRG microdata, the risk of information bias regarding mortality can be considered low because the reason for discharge (in case of mortality: death) has to be coded in the DRG system. The main diagnosis and procedures is most important for remuneration of a case and is controlled by the health insurance medical service (Medizinischer Dienst der Krankenkassen, MDK) in frequent audits. Secondary diagnoses will often only be coded if they are relevant to reimbursement, while relevant upcoding of secondary diagnosis is unlikely due to MDK audits [12, 32]. As anatomical details (e.g. side of the body, size of AAA, length of vessel occlusion) are irrelevant to remuneration, these data are not collected in this database. Among other unobserved factors, the latter characteristics may be a source of residual confounding [1]. Another issue is that in some cases secondary diagnoses present on presentation cannot be differed from a procedural complication (e.g. a patient presenting with an AAA and renal impairment cannot be differentiated from a patient presenting with AAA and normal renal function, who develops renal insufficiency after the procedure). Also, as a case ends after discharge, a shorter length of stay will lead to a shorter observation period. This might become important when comparing, e.g. open surgical vs. endovascular interventions, where the endovascularly treated patient will typically be discharged earlier.

The data of statutory quality assurance registries are self-reported by the treating physician or delegates of the department. Down-coding can therefore not be excluded. The risk of information bias in this case is highly dependent on internal validation of the entered data and external data validation. In the case of eQS data on carotid artery revascularization this was performed on a semiannual basis by the so-called federal state offices (Landesstellen) and the aQua Institute in structured validity checks and hospital

Gefässchirurgie 2019·24:220-227 https://doi.org/10.1007/s00772-019-0524-y

(c) The Author(s) 2019

\author{
M. Trenner · H.-H. Eckstein · M. A. Kallmayer · B. Reutersberg · A. Kühnl
}

\title{
Secondary analysis of statutorily collected routine data. Strengths, limitations and examples of use
}

\section{Abstract}

Real-world data are gaining increasing attention as an inevitable adjunct to the evidence gathered by randomized controlled trials (RCT). Registry data are often limited through voluntary participation of selected physicians, hospitals and patients (selection bias) as well as insufficient data validation (information bias); however, secondary analysis of statutorily collected data can overcome some of these limitations and enable nationwide (full) surveys to be conducted. This is especially important for the analysis of structural aspects of health care.
This article provides an introduction to the methodology of secondary data analysis of routine data in Germany that are collected on the basis of statutory regulations. The article emphasizes the strengths and limitations and gives an overview of possible applications, including recent examples focusing on vascular medicine.

\section{Keywords}

Health care surveys - Diagnosis-related groups · Germany · Vascular surgery · Quality assurance

\section{Sekundärdatenanalyse von verpflichtend erhobenen Routinedaten. Stärken, Schwächen und Anwendungsbeispiele}

\section{Zusammenfassung}

Routinedatenanalysen finden zunehmend Beachtung und sind eine unverzichtbare Ergänzung zur Evidenz aus randomisierten kontrollierten Studien. Registerdaten sind oft durch die freiwillige Teilnahme ausgewählter Krankenhäuser, Ärzte und Patienten (Selektionsbias) sowie eine fehlende Datenvalidierung (Informationsbias) eingeschränkt. Analysen von Daten, deren Sammlung gesetzlich vorgeschrieben ist, können einige dieser Limitationen überwinden und ermöglichen es, u.a. bundesweite Erhebungen durchzuführen. Dies ist besonders wichtig für die Analyse struktureller Aspekte des Gesundheitswesens. Dieser Artikel gibt eine Einführung in die Methodik der Sekundärdatenanalyse von Routinedaten in Deutschland, deren Sammlung gesetzlich vorgeschrieben ist. Er stellt die Stärken und Limitationen heraus und zeigt Anwendungsbeispiele aus der Gefäßmedizin.

\section{Schlüsselwörter}

Gesundheitsstudien - Diagnosebezogene Gruppen · Deutschland - Gefäßchirurgie . Qualitätssicherung audits, especially in hospitals whose complication rates were higher or lower than expected [16]. As only selected hospitals are validated, the risk of information bias should be considered at least intermediate in this database. Regarding confounders and length of stay, statutory quality assurance databases bear limitations comparable to DRG microdata. Information bias in health insurance data can be considered the same as in DRG microdata (low regarding mortality, intermediate regarding other outcomes and dependent on MDK audits). A huge strength of insurance data is the possibility to follow patients longitudinally and also outpatient diagnoses and pro- cedures are recorded. For registries, the main strength is that they can be designed to answer certain questions and therefore all data of interest (including clinical findings, laboratory tests, etc.) can potentially be recorded; however, the risk of bias in registries is highly dependent on data validation policies of the registry. Without internal (and external) data validation, the results and conclusions drawn may remain questionable $[25,35]$.

\section{Topics and examples of secondary data analysis}

With secondary data analysis of statutory routine data collections the health care 
provision for inpatients can be analyzed on a national level. The main topics are of an epidemiological nature but in-depth analysis of risk factors and regional differences of incidence and treatment strategies are also relevant issues [27]. The following sections give an overview of topics and recent publications on secondary data analysis of statutorily collected data in vascular surgery in Germany.

\section{Epidemiology and time trends}

\section{Epidemiology and inpatient treatment of vascular diseases in Germany}

In an analysis of hospital basic data and aggregated DRG statistics from 2005-2013 by Kuehnl et al. [15] it was found that the incidence of vascular diseases increased over time and especially male patients were affected. Most forms of treatment were conducted in general surgical or vascular surgical departments. The number of hospitals employing vascular specialists was found to have doubled in 2013 compared to 1991. While peripheral arterial occlusive disease (PAOD) and aortic aneurysms (AA) were treated mostly endovascularly, carotid revascularization and lower limb embolectomy was mostly treated by open surgery [15].

\section{Incidence, treatment and mortality of abdominal aortic aneurysms (AAA)}

Analyzing DRG microdata from 2005-2014 the hospital incidence of AAA treatment was found to be 27.9 and 3.3 cases per 100,000 inhabitants for men and women, respectively. A decreasing incidence of ruptured (r) AAA and increase of intact (i) AAA repair was described. Over the time period, the use of endovascular aneurysm repair (EVAR) in iAAA rose from $29 \%$ to $75 \%$ (rAAA from $8 \%$ to $36 \%)$. The overall in-hospital mortality of iAAA was $3.3 \%$ in men and $5.3 \%$ in women (rAAA $39 \%$ and 48\%, respectively). Mortality decreased over time [12].
Incidence, treatment and mortality of thoracic aortic aneurysm (TAA) and thoracoabdominal aortic aneurysm (TAAA) repair

Geisbuesch et al. analyzed DRG microdata of 48,098 cases of TAA (5848 rTAA, 42,250 iTAA). An increasing incidence was found for TAA (2006: 0.67/100,000; 2014: 1.14/100,000). The number of hospitals treating TAA doubled over time (2005: 89, 2014: 187) and $81.6 \%$ of cases were treated endovascularly. In-hospital mortality was $5 \%$ for iTAA and $25.2 \%$ for rTAA. Increasing age and comorbidity burden were found to be associated with an increased risk for in-hospital mortality [7].

In a second analysis, 12,102 cases of TAAA (2242 rTAAA, 9860 iTAAA) could be included. Analogue to TAA an increasing hospital incidence was found (2008: 0.31/100,000; 2014: 0.88/100,000), $54.5 \%$ of the patients were treated by open surgery overall but endovascular treatment was conducted in $76 \%$ of patients by 2014 . Therefore, a tremendous increase of endovascular treatment was found in this cohort. In-hospital mortality was $15.9 \%$ for iTAAA and $46.1 \%$ for rTAAA [6].

\section{Vascular complications in diabetic patients}

Looking at 1,811,422 cases, 2 studies analyzed DRG microdata with respect to the severity of vascular complications and temporal changes of treatment methods in patients with diabetes. Of the patients two thirds were male with a median age of 73 years. There were no changes seen in the total number of amputations but a decrease of above-knee amputations (by $31 \%$ ) and below-knee amputations (by $41 \%)$ was shown. Minor amputations increased by $18 \%$. Revascularization procedures increased from 36/100,000 inhabitants in 2005 to $48 / 100,000$ inhabitants in 2014. This was mainly driven by an increase of endovascular interventions. In summary, it was shown that a higher rate of revascularization was associated with lower rates of major amputation and an increase of minor amputation in diabetic patients $[20,21]$.
Treatment and outcomes of carotid artery revascularization

Using the statutorily collected eQS data, an almost complete record of revascularization procedures of the carotid artery can be achieved. An analysis was conducted for all elective carotid endarterectomies (CEA, 2009-2014) and carotid artery stenting (CAS, 2012-2014) whereby 142,074 CEA (67.8\% male) and 13,086 CAS (69.7\% male) were included. The primary outcome of this study, published by Eckstein et al. was the combined stroke rate and mortality during inpatient stay. In addition to the descriptive analysis of the raw data, a risk-adjusted analysis of the association of clinical characteristics (e.g. age, sex, neurologic presentation, etc.) with the risk of stroke and mortality was performed. Approximately $60 \%$ of patients who were electively treated with CEA and CAS were clinically asymptomatic. The median age was 72 years (CEA) and 71 years (CAS). The periprocedural stroke rate/fatality of CEA was $1.4 \%$ in asymptomatic and $2.5 \%$ in symptomatic stenoses; in CAS it was $1.7 \%$ and $3.7 \%$, respectively. The following variables were significantly associated with increased risk: increasing age, the American Society of Anesthesiologists (ASA) classification, symptomatic versus asymptomatic stenosis, 50-69\% stenosis grade, and contralateral carotid closure (demonstrated only with CEA); however, the available data did not allow an appropriate statistical comparison of the two methods [3].

Temporal trends in CEA and CAS between 2003 and 2014 were analyzed in a study published by Kallmayer et al. [8] where 309,405 cases of CEA and 18,047 cases of CAS could be included. An increase of patients with ASA grade III-V was shown for CEA (2003: 65\% and 2014: 71\%), while in CAS the proportion of these patients decreased ( $44 \%$ to $41 \%$ ). The delay between surgery and the neurological index event in symptomatic patients decreased significantly (from 28 days to 8 days; $p<0.0001$ ). There were significant trends for performing CEA on patients under local anesthesia $(10.1 \%$ to $29.1 \% ; p<0.001)$ and using the eversion technique (37.0\% to $41.6 \%$; 
$p<0.001)$. The rate of in-hospital stroke or death decreased from $2.0 \%$ to $1.1 \%$ in asymptomatic CEA patients without contralateral occlusion or high grade stenosis $(p<0.001)$, while it remained stable in CAS $(1.7 \%$ to $1.8 \%, p=0.909)$. No significant trends were seen for patients with contralateral high grade stenosis or occlusion. In symptomatic patients, the event rate was significantly reduced after CEA from $4.2 \%$ to $2.4 \%$ $(p<0.001)$ and remained stable after CAS $(3.9 \%$ to $3.5 \%, p=0.577)$. In summary, the patients receiving CEA in this analysis became older over time and presented with more comorbidities, while the in-hospital rate of stroke or death decreased [8].

A total of 5058 patients suffering stroke-in-evolution (SIE) and receiving carotid revascularization were included in a study by Knappich et al. [10]. For 3176 patients receiving CEA and 1882 receiving CAS, patient characteristics and in-hospital outcomes were described. Emergency carotid revascularization was associated with a new postoperative stroke or all-cause death before discharge in $9.0 \%$ of patients receiving CEA and $11.7 \%$ of patients receiving CAS. A multilevel multivariable regression analysis revealed that lower age, lower ASA classification, lower grade of stenosis and less severe neurological deficits preceding CEA were associated with a lower rate of postprocedural stroke or death and may thus be interpreted as possible protective factors [10].

\section{Comparisons and risk factors}

\section{Risk factors for AAA repair}

Looking at 84,631 cases of AAA repair (11.9\% females), Trenner et al. identified female sex (RR 1.20 [1.07-1.35]) and age (RR per 10-year increase 1.83 [1.73-1.95]) as independent risk factors for iAAA repair. It was also found that women were significantly older on admission than men ( 74 years, range $69-80$ years vs. 72 years, range $66-77$ years; $p<0.001)$ and that EVAR was used less frequently in women $(48.1 \%$ vs. $54.7 \%$ $p<0.001$ ) [31].

\section{Risk factors for TAA and TAAA repair}

Apart from describing the incidence of TAA and TAAA, the abovementioned analyses by Geisbüsch et al. investigated risk factors of TAA(A) repair. It was found that rupture, increasing age, and higher comorbidity burden were significantly associated with higher mortality in TAA repair (risk ratio, RR: 6.66 [5.33-8.25], 1.28 [1.17-1.40] and 1.06 [1.05-1.08], respectively). Endovascular treatment was associated with lower mortality (RR 0.31 [0.23-0.41]). Noassociation between annual hospital volume and mortality was found for TAA repair [7]. The same clinical risk factors were identified for TAAA (rupture RR: 3.17 [2.45-4.09], increasing age per 10 years 1.57 [1.32-1.76] and comorbidity score per 1 point increase 1.05 [1.04-1.06], endovascular therapy 0.35 [0.24-0.51]). In contrast to TAA, an inverse association of annual hospital caseload with in-hospital mortality was shown for TAAA in this analysis [6].

\section{Risk factors for carotid revascularization}

Age and sex. Based on the eQS data, it was shown that in CEA procedures the adjusted risk of perioperative stroke or death was significantly associated with the patient's age $(\mathrm{RR}=1.19$ per 10 years, $95 \%$ confidence interval, CI 1.14-1.24) but not with sex [24]. The CAS also showed a comparable age effect $(\mathrm{RR}=1.54,95 \%$ CI $1.35-1.75)$ and no influence of sex. Interestingly, when comparing CEA with CAS, the association with the secondary endpoint stroke (alone) in CAS was significantly associated with age [23] but weaker in CEA $(\mathrm{RR}=1.47,95 \%$ CI $1.26-1.72$ vs. $\mathrm{RR}=1.05,95 \%$ CI $1.00-1.11$, respectively). The latter observation is consistent with results from a metaanalysis of the Carotid Stenting Trialists' Collaboration (CSTC) and affirms that the indication for CAS in older patients should be viewed with particular caution $[2,23]$. These results support the notion that patients' age should be included as a factor for risk assessment/adjustment when choosing the procedure (CEA vs. CAS). In addition, other individual factors were identified (e.g. ASA classification, grade of stenosis, etc.) that were associated with a higher or lower risk of CEA and CAS $[4,23,24]$.

Procedural factors. The eQS data showed that the use of local anesthesia, performing CEA with patch plasty, intraoperative control of the vascular reconstruction, and a short clamping time were significantly associated with a lower risk of stroke or death [9]. For patients treated with CAS, the only technical procedural factor associated with a lower risk of stroke and death was the use of an embolic protection device [11]. The largest RCT to date comparing local and general anesthesia in CEA (GALA trial), showed a protective but not significant beneficial effect of local anesthesia [17]. A metaanalysis of four additional RCTs (primary comparison CEA vs. CAS) showed a concurrent but also not significant advantage for local anesthesia. The combination of the results of all five RCTs revealed a significant protective effect of local anesthesia, presumably due to the larger number of cases. It remained unclear which patient group under which conditions would benefit the most from local or general anesthesia [2].

Time interval between neurological index event and treatment. The optimal time frame for CEA or CAS in symptomatic patients is the subject of much discussion in the vascular community. Guidelines $[3,5,18,19,22]$ recommend that CEA should be performed as soon as possible after the index event, as a moderate to high recurrence rate is expected [34]. In contrast, other studies indicated that delaying CEA or CAS by a few days could be beneficial $[26,30]$. In the analyses based on the eQS data, this group has shown that for CAS there is a significant association between a short time interval and high risk for stroke or death [33] but not for CEA [34]. What remained unclear was the factors associated with delayed treatment under routine conditions and how these could be modulated to improve the quality of care.

Perioperative antiplatelet therapy. The absence of a clear consensus regarding 
perioperative antiplatelet therapy for carotid surgery was the reason for an analysis published by Zimmerman et al. [36]. Associations between different antiplatelet regimens and the perioperative risk of stroke or death and complications were analyzed using eQS data. Of the patients $80 \%$ received aspirin as single antiplatelet agent, $3 \%$ received other agents and 5\% were operated on under dual antiplatelet therapy. Regression analysis revealed a significantly elevated relative risk for any stroke or death rate in patients receiving no antiplatelet therapy (RR 1.21; 95\% CI 1.04-1.42) compared to patients under monotherapy. The same was shown for the risk of major stroke or death (RR 1.23; 95\% CI 1.02-1.48). Dual antiplatelet therapy was associated with a lower risk of death (RR 0.67; 95\% CI 0.51-0.88) but with higher rates of bleeding complications requiring surgery ( $R R \quad 2.16 ; 95 \% \mathrm{CI}$ 1.88-2.50). In summary, perioperative antiplatelet therapy was associated with a decreased risk of in-hospital stroke or death but with a higher risk of bleeding regarding dual therapy [36].

\section{Volume-outcome relationships for AAA and carotid revascularization}

Structural aspects of healthcare, such as volume-outcome relationships, are a main interest of secondary data analysis of statutorily collected data. As data submission and collection are regulated by law, hospitals that only treat a small number of cases are also captured in these data sets. This is particularly interesting as these hospitals typically do not participate in voluntary registries.

An analysis of DRG microdata revealed that between 2005 and $2013>700$ hospitals treated AAA in Germany. A total of 96,426 AAA cases (12.6\% rAAA) were included in a volume-outcome analysis. Hospitals were divided into quartiles, depending on their annual volume of all AAA repairs (Q1 1-5, Q2 6-14, Q3 15-30, Q4 >30 cases per year). Annual hospital volume was inversely associated with in-hospital mortality for iAAA (RR Q1 1.61 [1.30-1.98]; Q2 1.28 [1.11-1.48]; Q3 1.20 [1.07-1.36]; $\mathrm{Q} 4=$ reference $)$ and $\mathrm{rAAA}$ repair $(\mathrm{RR} \mathrm{Q} 1$
1.73 [1.46-2.05]; Q2 1.46 [1.28-1.67]; Q3 1.22 [1.10-1.35]; Q4= reference). Similar associations were found for complication rates (peripheral embolism and thrombosis, bowel resection, amputation) and use of blood products. When analyzing hospital volume as a continuous variable, the lowest relative risk for in-hospital mortality was found for hospitals treating 75-100 AAA cases per year [32].

Associations between annual hospital caseload and stroke or death after CAS and CEA were analyzed on a national level using eQS data from 2009 to 2014 and 161,448 CEA and 17,575 CAS procedures were included. For CEA the crude risk of stroke or death was $4.2 \%$ (95\% CI $3.6-4.9 \%$ ) in low-volume hospitals (first quintile: 1-10 CEA/year) and monotonically decreased to $2.1 \%(2.0-2.2 \%)$ in high-volume hospitals (fifth quintile: $\geq 80$ /year; $p<0.001$ for trend). For CAS the overall risk was $3.7 \%$ (3.5-4.0\%) but no association with annual caseload was shown $(p=0.304)$. The volume-outcome effect for CEA remained true in multivariable analysis [16].

\section{Regional variations}

The analysis of regional variations of diseases is necessary for planning and restructuring healthcare provision. In analoge to volume-outcome analysis, statutorily collected data are indispensable for this purpose as all relevant cases are included in these databases.

\section{Regional variations in AAA}

The DRG statistics from 2011-2014 were included in an analysis focusing on regional variations of hospital incidence of AAA in Germany and 50,702 cases were included. The standardized regional incidence varied widely from 6.3 to 30.3 per 100,000 inhabitants (overall: $15.7 / 100,000)$. The highest regional incidences were found in the northwestern parts of Germany, whereas southern and eastern regions showed below average incidences. Mortality rates did not significantly differ [13].

\section{Regional variations in carotid revascularization}

Variations of carotid artery procedure rates among German regions, as well as regional characteristics that were associated with the frequency of procedures, were investigated using aggregated DRG statistics from 2012 to 2014 in an analysis published by Kuehnl et al. [14] and 73,042 cases undergoing CEA and 15,367 cases undergoing CAS were included. Indirect standardization was applied to adjust for age and sex-dependent differences. The lowest overall procedure rate was found for the Augsburg region $(13.2 / 100,000)$, while the highest rate was found for the Wilhelmshaven region $(89.2 / 100,000)$. The regional distribution was significantly clustered in spatial analysis. The CEA and especially CAS rates showed high regional variations. Regional prevalence of diabetes, as well as smoking and obesity, socioeconomic factors (income, debts) were correlated with the frequency of carotid procedures. No association between density of vascular specialists (vascular surgeon and angiologists) or hospital beds with overall procedure rates was found [14].

\section{Practical conclusion}

- Real-world data can be considered an inevitable adjunct to the evidence gained by RCTs.

- Secondary data analysis of statutorily collected routine data is able to include nearly all cases treated nationwide and thus, selection bias may be considered low.

- The risk of information bias in statutorily collected data can be considered low regarding hard outcomes (e.g. mortality) but the frequency of secondary outcomes (e.g. complications) might be underestimated.

- Nationwide data are crucial for structural analysis of healthcare supply (volume-outcome associations, regional variations). 


\section{Corresponding address}

Dr. med. M. Trenner
Klinik und Poliklinik für
Vaskuläre und Endovaskuläre
Chirurgie, Klinikum rechts der
Isar, Technische Universität
München, Fakultät für
Medizin
Ismaninger Str. 22,
81675 Munich, Germany
matthias.trenner@mri.tum.de

\section{Compliance with ethical guidelines}

Conflict of interest M. Trenner, H.-H. Eckstein, M.A. Kallmayer, B. Reutersberg and A. Kühnl declare that they have no competing interests.

For this article no studies with human participants or animals were performed by any of the authors. All studies performed were in accordance with the ethical standards indicated in each case.

Open Access. This article is distributed under the terms of the Creative Commons Attribution 4.0 International License (http://creativecommons.org/licenses/by/ 4.0/), which permits unrestricted use, distribution and reproduction in any medium, provided you give appropriate credit to the original author(s) and the source, provide a link to the Creative Commons license, and indicate if changes were made.

\section{References}

1. Behrendt CA, Debus ES, Mani K et al (2018) The strengths and limitations of claims based research in countries with fee for service reimbursement. Eur JVasc Endovasc Surg 56:615-616

2. Carotid Stenting Trialists C, Bonati LH, Dobson J et al (2010) Short-term outcome after stenting versus endarterectomy for symptomatic carotid stenosis: a preplanned meta-analysis of individual patient data. Lancet 376:1062-1073

3. Eckstein HH, Kühnl A, Dörfler A et al (2013) The diagnosis, treatment and follow-up of extracranial carotid stenosis. Dtsch Arztebl Int 110:468-476

4. Eckstein HH, Tsantilas P, Kuhnl A etal (2017) Surgical and Endovascular treatment of extracranial carotid stenosis. Dtsch Arztebl Int 114:729-736

5. FurieKL, KasnerSE, AdamsRJetal (2011) Guidelines for the prevention of stroke in patients with stroke or transient ischemic attack: a guideline for healthcare professionals from the american heart association/american stroke association. Stroke 42:227-276

6. Geisbusch S, Kuehnl A, Salvermoser M et al (2018) Hospital incidence, treatment, and in-hospital mortality following open and endovascular surgery for thoracoabdominal aortic aneurysms in Germany from 2005 to 2014 Secondary data analysis of the nationwide German DRG microdata. Eur JVasc Endovasc Surg. https://doi.org/10.1016/ j.ejvs.2018.10.030

7. Geisbusch S, Kuehnl A, Salvermoser $M$ et al (2018) Increasing Incidence of Thoracic Aortic Aneurysm Repair in Germany in the Endovascular
Era: Secondary Data Analysis of the Nationwide German DRG Microdata. Eur J Vasc Endovasc Surg https://doi.org/10.1016/j.ejvs.2018.08.013

8. Kallmayer MA, Tsantilas P, Knappich C et al (2015) Patient characteristics and outcomes of carotid endarterectomy and carotid artery stenting: analysis of the German mandatory national quality assurance registry -2003 to 2014. J Cardiovasc Surg (Torino) 56:827-836

9. Knappich C, Kuehnl A, Tsantilas P et al (2017) Intraoperative completion studies, local anesthesia, and Antiplatelet medication are associated with lower risk in carotid endarterectomy. Stroke 48:955-962

10. Knappich C, Kuehnl A, Tsantilas P et al (2018) Patient characteristics and in-hospital outcomes of emergency carotid endarterectomy and carotid stenting after stroke in evolution. J Vasc Surg 68:436-444 (e436)

11. Knappich C, Kuehnl A, Tsantilas P et al (2017) The use of embolic protection devices is associated with a lower stroke and death rate after carotid stenting. JACC Cardiovasc Interv 10:1257-1265

12. Kuehnl A, Erk A, Trenner M et al (2017) Incidence, treatment and mortality in patients with abdominal aortic aneurysms - a secondary analysis of diagnosis-related groups (DRG) data from 2005-2014. Dtsch Arztebl Int 114:391-398

13. Kuehnl A, Salvermoser M, Erk A et al (2018) Spatial analysis of hospital incidence and in hospital mortality of abdominal aortic aneurysms in Germany: secondary data analysis of nationwide hospital episode (DRG) data. Eur J Vasc Endovascular Surg 55:852-859

14. Kuehnl A, Salvermoser M, Knipfer E et al (2018) Regional frequency variation of revascularization procedures for carotid stenosis in Germany: Secondary data analysis of DRG data from 2012 to 2014. Gefasschirurgie 23:56-65

15. Kuehnl A, Söllner H, Eckstein H-H (2015) Epidemiologie und stationäre Versorgung von vaskulären Erkrankungen in Deutschland. Gefasschirurgie 20:204-213

16. Kuehnl A, Tsantilas P, Knappich C et al (2016) Significant Association of Annual Hospital Volume With the Risk of Inhospital Stroke or Death Following Carotid Endarterectomy but Likely Not After Carotid Stenting: Secondary Data Analysis of the Statutory German Carotid Quality Assurance Database. Circ Cardiovasc Interv 9. https://doi.org/ 10.1161/circinterventions.116.004171

17. Lewis SC, Warlow CP, Bodenham AR et al (2008) General anaesthesia versus local anaesthesia for carotid surgery (GALA): a multicentre, randomised controlled trial. Lancet 372:2132-2142

18. Liapis CD, Bell PR, Mikhailidis D et al (2009) ESVS guidelines. Invasive treatment for carotid stenosis: indications, techniques. Eur J Vasc Endovasc Surg 37:1-19

19. National Collaborating Centre for Chronic Conditions (Uk) (2008) Stroke: National clinical guideline for diagnosis and initial management of acute stroke and transiend ischaemic attack (TIA). Royal College of Physicians, London

20. Olm M, Kuehnl A, Knipfer E et al (2018) Change in hospital indicators for diabetics with vascular complications in Germany: Secondary data analysis of DRG statistics from 2005 to 2014. Gefaesschirurgie 23(6):452-458. https://doi.org/ 10.1007/s00772-018-0386-8

21. Olm M, Kuhnl A, Knipfer E et al (2018) Operative treatment of diabetics with vascular complications: Secondary data analysis of diagnosis-related groups statistics from 2005 to 2014 in Germany. Chirurg 89:545-551
22. Ricotta JJ, Aburahma A, Ascher E et al (2011) Updated Society for Vascular Surgery guidelines for management of extracranial carotid disease. JVasc Surg 54:e1-31

23. Schmid S, Tsantilas P, Knappich C et al (2018) Age but not sex is associated with higher risk of in-hospital stroke or death after carotid artery stenting in symptomatic and asymptomatic carotid stenosis. J Vasc Surg. https://doi.org/10. 1016/j.jvs.2018.03.439

24. Schmid S, Tsantilas P, Knappich C et al (2017) Risk of Inhospital stroke or death is associated with Age but not sex in patients treated with carotid endarterectomy for asymptomatic or symptomatic Stenosis in routine practice: secondary data analysis of the nationwide German statutory quality assurance database from 2009 to 2014 . J Am Heart Assoc 6. https://doi.org/10.1161/jaha. 116.004764

25. Schmitz-Rixen T, Jung G, Steffen M et al (2018) Registerdaten sind elementar zu den prospektiv randomisierten Studien. Gefasschirurgie 23:346-353

26. Stromberg S, Gelin J, Osterberg T et al (2012) Very urgent carotid endarterectomy confers increased procedural risk. Stroke 43:1331-1335

27. Swart E (2014) Routinedaten im Gesundheitswesen - Handbuch Sekundärdatenanalyse: Grundlagen, Methoden und Perspektiven. Huber, Hogrefe, Bern

28. Swart E, Bitzer EM, Gothe H et al (2016) STandardisierte BerichtsROutine für Sekundärdaten Analysen (STROSA) - ein konsentierter Berichts standard für Deutschland, Version 2. gesu 78:145-160

29. Swart E, Gothe H, Geyer Set al (2015) Good Practice of Secondary Data Analysis (GPS): guidelines and recommendations. Gesundheitswesen 77:120-126

30. Tanious A, Pothof AB, Boitano LT et al (2018) Timing of carotid endarterectomy after stroke: retrospective review of prospectively collected national database. Ann Surg 268:449-456

31. Trenner M, Kuehnl A, Reutersberg B et al (2018) Nationwide analysis of risk factors for in-hospital mortality in patients undergoing abdominal aortic aneurysm repair. Br J Surg 105:379-387

32. Trenner M, Kuehnl A, Salvermoser M et al (2018) Editor's choice: high annual hospital volume is associated with decreased in hospital mortality and complication rates following treatment of abdominal aortic aneurysms: secondary data analysis of the nationwide German DRG statistics from 2005 to 2013. Eur J Vasc Endovasc Surg 55(2):185-194

33. Tsantilas P, Kuehnl A, Kallmayer Met al (2018) Risk of stroke or death is associated with the timing of carotid artery Stenting for symptomatic carotid Stenosis: a secondary data analysis of the German statutory quality assurance database. J Am Heart Assoc 7. https://doi.org/10.1161/jaha.117.007983

34. Tsantilas P, Kuehnl A, Konig T et al (2016) Short time interval between Neurologic event and carotid surgery is not associated with an increased procedural risk. Stroke 47:2783-2790

35. Venermo M, Mani K, Kolh P (2017) The quality of a registry based study depends on the quality of the data-without validation, it is questionable. Eur JVas Endovasc Surg 53:611-612

36. Zimmermann A, Knappich C, Tsantilas Pet al (2018) Different perioperative antiplatelet therapies for patients treated with carotid endarterectomy in routine practice. J Vasc Surg. https://doi.org/10. 1016/j.jvs.2018.01.063 